\title{
First-Principles Design of Rutile Oxide Heterostructures for Oxygen Evolution Reactions
}

\author{
Hyeong Yong Lim, Sung O Park, Su Hwan Kim, Gwan Yeong Jung * and Sang Kyu Kwak* \\ School of Energy and Chemical Engineering, Ulsan National Institute of Science and Technology (UNIST), Ulsan, South Korea
}

OPEN ACCESS

Edited by:

Kai S. Exner,

Sofia University, Bulgaria

Reviewed by:

Marko Melander,

University of Jyväskylä, Finland

Herbert Over,

University of Giessen, Germany

*Correspondence:

Gwan Yeong Jung

gyjung@unist.ac.kr

Sang Kyu Kwak

skkwak@unist.ac.kr

Specialty section:

This article was submitted to

Electrochemical Energy

Conversion and Storage,

a section of the journal

Frontiers in Energy Research

Received: 14 September 2020

Accepted: 05 January 2021

Published: 11 February 2021

Citation:

Lim HY, Park SO, Kim SH, Jung GY and Kwak SK (2021) First-Principles

Design of Rutile

Oxide Heterostructures for Oxygen

Evolution Reactions.

Front. Energy Res. 9:606313.

doi: 10.3389/fenrg.2021.606313
The oxygen evolution reaction (OER) plays a key role in the determination of overall watersplitting rate. Lowering the high overpotential of the OER of transition metal oxides (TMOs), which are used as conventional OER electrocatalysts, has been the focus of many studies. The OER activity of TMOs can be tuned via the strategic formation of a heterostructure with another TMO substrate. We screened 11 rutile-type TMOs (i.e., $\mathrm{MO}_{2} ; \mathrm{M}=\mathrm{V}, \mathrm{Cr}, \mathrm{Mn}, \mathrm{Nb}$, $\mathrm{Ru}, \mathrm{Rh}, \mathrm{Sn}, \mathrm{Ta}, \mathrm{Os}, \mathrm{Ir}$, and Pt) on a rutile (110) substrate using density functional theory calculations to determine their OER activities. The conventional volcano approach based on simple binding energies of reaction intermediates was implemented; in addition, the electrochemical-step symmetry index was employed to screen heterostructures for use as electrode materials. The results show that $\mathrm{RuO}_{2}$ and $\mathrm{IrO}_{2}$ are the most promising catalysts among all candidates. The scaling results provide insights into the intrinsic properties of the heterostructure as well as materials that can be used to lower the overpotential of the OER.

Keywords: density functional theory, oxygen evolution reaction, rutile-type oxide, heterostructure, scaling relation

\section{INTRODUCTION}

Green hydrogen production remains a challenge that must be overcome to achieve a hydrogen economy (Turner, 2004). Water electrolysis is one of the approaches toward hydrogen ecofriendliness. It is based on the hydrogen evolution reaction (HER) and oxygen evolution reaction (OER) as cathodic and anodic reactions, respectively. However, the slow kinetics of the OER limit the commercialization of this approach. Oxide systems based on $\mathrm{Ir}$ or $\mathrm{Ru}$ (i.e., $\mathrm{IrO}_{x}$ or $\mathrm{RuO}_{x}$ ) are known to have the best OER performances (Lee et al., 2012; Frydendal et al., 2014; Suen et al., 2017). However, these materials are expensive. Therefore, many studies have been conducted to identify a cost-effective alternative oxide material with high activity. For example, transition-metal substitution (García-Mota et al., 2011) and the introduction of oxygen vacancies (Xiao et al., 2020) have been studied as means to control the compositions of expensive materials. However, transitionmetal substitution and oxygen vacancies only locally affect the active sites.

To activate the metal oxide, support materials are mixed with the oxide to enhance the electrical conductivity and activity of the electrocatalytic reaction (Kumar et al., 2016; Qingxiang et al., 2018; $\mathrm{Bu}$ et al., 2019; Lu et al., 2019). In addition, research on heterostructures is conducted with the goal of activating the material on the substrate. Modifications are mainly based on the strain effect and charge transfer due to the formation of an interface between the support material and catalyst. For instance, the heterostructure of $\mathrm{La}_{0.5} \mathrm{Sr}_{0.5} \mathrm{CoO}_{3-\delta}$ and $\mathrm{MoSe}_{2}$ induces the phase transition of $\mathrm{MoSe}_{2}$ from the $2 \mathrm{H}$ to the $1 \mathrm{~T}$ phase (Oh et al., 2019). In addition, the charge transfer from the Co ion to Mo ion improves the electrochemical activity. The results of another study showed that the heterostructure of $\mathrm{IrO}_{\mathrm{x}}$ and $\mathrm{SrIrO}_{3}$ outperforms iridium or ruthenium oxide systems (Seitz et al., 
2016). Based on density functional theory (DFT) calculations, $\mathrm{IrO}_{3}$ or anatase $\mathrm{IrO}_{2}$ motifs are formed during strontium leaching in the outermost surface layers of $\mathrm{SrIrO}_{3}$ and contribute to the high activity. Another strength of the heterostructure is that it can possibly contribute to reducing the use of precious metals by replacing them into low-cost metals while maintaining similar intrinsic activity of each active site (Esposito et al., 2010; Zhou et al., 2014; Wang et al., 2015; Jin et al., 2016). Rutile $\left(\mathrm{TiO}_{2}\right)$ is a well-known substrate material for metal oxide systems because of its high structural stability and simple structure (Hanaor et al., 2012). It is suitable for the growth of oxide films, facilitating the fabrication of heterostructures with various metal oxides. In addition, rutile affects the catalytic activity of metal oxides and has a high cost effectiveness (Seitsonen and Over, 2010; Stacchiola et al., 2013; Wei et al., 2015; Sun et al., 2016; Li et al., 2017). However, the effect of the rutile support on the activity remains unclear due to difficulties with respect to the characterization of the heterostructure during experiments (Stacchiola et al., 2013).

In this study, we performed DFT calculations to theoretically investigate the effect of the $\mathrm{TiO}_{2}$ substrate on the heterostructure and thus on the OER. We screened the OERs of heterostructures consisting of various rutile-type metal oxides (i.e., $\mathrm{VO}_{2}, \mathrm{CrO}_{2}, \mathrm{MnO}_{2}, \mathrm{NbO}_{2}, \mathrm{RuO}_{2}, \mathrm{RhO}_{2}, \mathrm{SnO}_{2}$, $\mathrm{TaO}_{2}, \mathrm{OsO}_{2}, \mathrm{IrO}_{2}$, and $\mathrm{PtO}_{2}$ ) and a $\mathrm{TiO}_{2}$ substrate. The results show that these rutile heterostructures follow the universal scaling relations of metals and oxides; however, the binding strengths of the $\mathrm{O}^{*}$ intermediates increase due to the $\mathrm{TiO}_{2}$ substrate. The volcano plot and electrochemical-step symmetry index (ESSI) show that the $\mathrm{RuO}_{2}$ and $\mathrm{IrO}_{2}$ are the closest to an ideal catalyst. The results of our computational screening provide insights into the effects of support materials on electrocatalytic reactions.

\section{METHODS}

Spin-polarized DFT calculations were performed with the projector-augmented wave (PAW) method (Blochl, 1994) and Vienna Ab initio Simulation Package (VASP) (Kresse and Furthmiiller, 1996). The electron exchange-correlation energy was treated within the generalized gradient approximation (GGA) and the Perdew-Burke-Ernzerhof functional (Perdew et al., 1997). To determine the trend of the OER activity, the DFT + U method within Liechtenstein's approach (Anisimovdag et al., 1997) was used and the following correction parameters were employed: $\mathrm{U}=4.95 \mathrm{eV}$ for $\mathrm{Ti}$, $2 \mathrm{eV}$ for $\mathrm{V}, 7.15 \mathrm{eV}$ for $\mathrm{Cr}, 6.63 \mathrm{eV}$ for $\mathrm{Mn}, 3.32 \mathrm{eV}$ for $\mathrm{Nb}$, $6.73 \mathrm{eV}$ for $\mathrm{Ru}, 5.97 \mathrm{eV}$ for $\mathrm{Rh}, 5.91 \mathrm{eV}$ for Ir, and $6.25 \mathrm{eV}$ for Pt (Xu et al., 2015). The energy cutoff for the plane wave basis set was set at $520 \mathrm{eV}$. The geometry was optimized using the residual minimization method and the direct inversion in the iterative subspace method (RMM-DIIS) algorithm until the net force on each atom was below $0.02 \mathrm{eV} \cdot \AA^{-1}$, and the total energy was $10^{-6} \mathrm{eV}$ per atom. Dipole slab corrections were also applied to all slab model calculations. The $k$-point sampling of the Brillouin zone was done with a $4 \times 4 \times 1$ for bulk calculations and $6 \times 6 \times 8$ for slab calculations.

\section{RESULTS AND DISCUSSION}

To theoretically investigate the OER activities of rutile-type heterostructures, we considered the heterostructures of 11 rutile-type oxides (i.e., $\mathrm{MO}_{2}$, where $\mathrm{M}=\mathrm{V}, \mathrm{Cr}, \mathrm{Mn}, \mathrm{Nb}$, $\mathrm{Ru}, \mathrm{Rh}, \mathrm{Sn}, \mathrm{Ta}, \mathrm{Os}, \mathrm{Ir}$, and $\mathrm{Pt}$ ) with $\mathrm{TiO}_{2}$ substrate. To accurately illustrate the OER activity, the following magnetic structures were used for all calculations according to $\mathrm{Xu}$ et al.'s work: nonmagnetic (NM) for $\mathrm{TiO}_{2}, \mathrm{NbO}_{2}, \mathrm{RuO}_{2}, \mathrm{RhO}_{2}, \mathrm{IrO}_{2}$, and $\mathrm{PtO}_{2}$, and ferromagnetic (FM) for $\mathrm{CrO}_{2}$ and $\mathrm{MnO}_{2}$ (Xu et al., 2015). Furthermore, the ground state magnetic configurations of the other candidate models were identified as $\mathrm{FM}$ for $\mathrm{VO}_{2}$ and $\mathrm{NM}$ for $\mathrm{SnO}_{2}, \mathrm{TaO}_{2}$, and $\mathrm{OsO}_{2}$, respectively (Supplementary Figure S1). Surface models, that is, six-layer stoichiometric slabs, were built by using the $2 \times 1$ supercell of the optimized unit cell. The vacuum of $\sim 15 \AA$ was applied in the (110) direction, which is the most stable facet of rutile-type oxides (Figure 1A; Kung, 1989). Note that a tri-layer consisting of oxygen-metal-oxygen (O-M-O) atomic layers was considered to be a single layer in our slab models. The top four layers of the slab models were allowed to fully relax. The two layers at the bottom were fixed to represent the bulk state. For heterostructures, the top three layers of the $\mathrm{TiO}_{2}$ slab model were replaced with $\mathrm{MO}_{2}$ layers while maintaining the cell dimensions of the $\mathrm{TiO}_{2}$ substrate. The coordinatively unsaturated sites (CUS) of the metal atoms at the top surface were considered to be the adsorption sites for each intermediate (i.e., $\mathrm{OH}^{*}, \mathrm{O}^{*}$, and $\mathrm{OOH}^{*}$ ) for the OER. To examine the oxygen coverage effect on the OER activity, the pristine and fully $\mathrm{O}^{*}$ covered surfaces were representatively compared (i.e., denoted as $2 \mathrm{O}_{\mathrm{b}}$ and $2 \mathrm{O}_{\mathrm{b}} 2 \mathrm{O}_{c}$, where the subscripts " $\mathrm{b}$ " and " $\mathrm{c}$ " represent the bridge sites and CUS, respectively).

The overall OER process consists of four elementary steps involving proton-coupled electron transfer (PCET; Figure 1B) (Hammes-Schiffer, 2015; Costentin and Savéant, 2017). In this study, we followed the conventional four-electron pathways with respect to the OER of rutile heterostructures, which can be described as follows:

$$
\begin{gathered}
\mathrm{H}_{2} \mathrm{O}_{(\mathrm{l})}+\mathrm{M} \rightarrow \mathrm{MOH}^{*}+\left(\mathrm{H}^{+}+\mathrm{e}^{-}\right) \\
\mathrm{MOH}^{*} \rightarrow \mathrm{MO}^{*}+\left(\mathrm{H}^{+}+\mathrm{e}^{-}\right) \\
\mathrm{MO}^{*}+\mathrm{H}_{2} \mathrm{O}_{(\mathrm{l})} \rightarrow \mathrm{MOOH}^{*}+\left(\mathrm{H}^{+}+\mathrm{e}^{-}\right) \\
\mathrm{MOOH}^{*} \rightarrow \mathrm{M}+\mathrm{O}_{2(\mathrm{~g})}+\left(\mathrm{H}^{+}+\mathrm{e}^{-}\right) .
\end{gathered}
$$

The adsorption free energy was calculated using the following equation:

$$
\Delta G=\Delta E+\Delta Z P E-T \Delta S-e U+k_{\mathrm{B}} T \ln a_{\mathrm{H}^{+}},
$$

where $\Delta E$ is the binding energy of each reaction intermediate; $\triangle Z P E$ is the zero-point vibrational enthalpy; $-T \Delta S$ is the entropic correction at room temperature, $-e U$ is the energy shift by the electrode potential, where $U$ is the electrode applied potential relative to the standard hydrogen electrode (SHE) and $e$ is the elementary charge transferred; and $k_{\mathrm{B}} T \ln a_{H^{+}}$is used as correction for the free energy of $\mathrm{H}^{+}$ions, where $a_{\mathrm{H}^{+}}$is the activity of the proton. In this study, we considered the standard conditions for Gibbs free energy calculations 


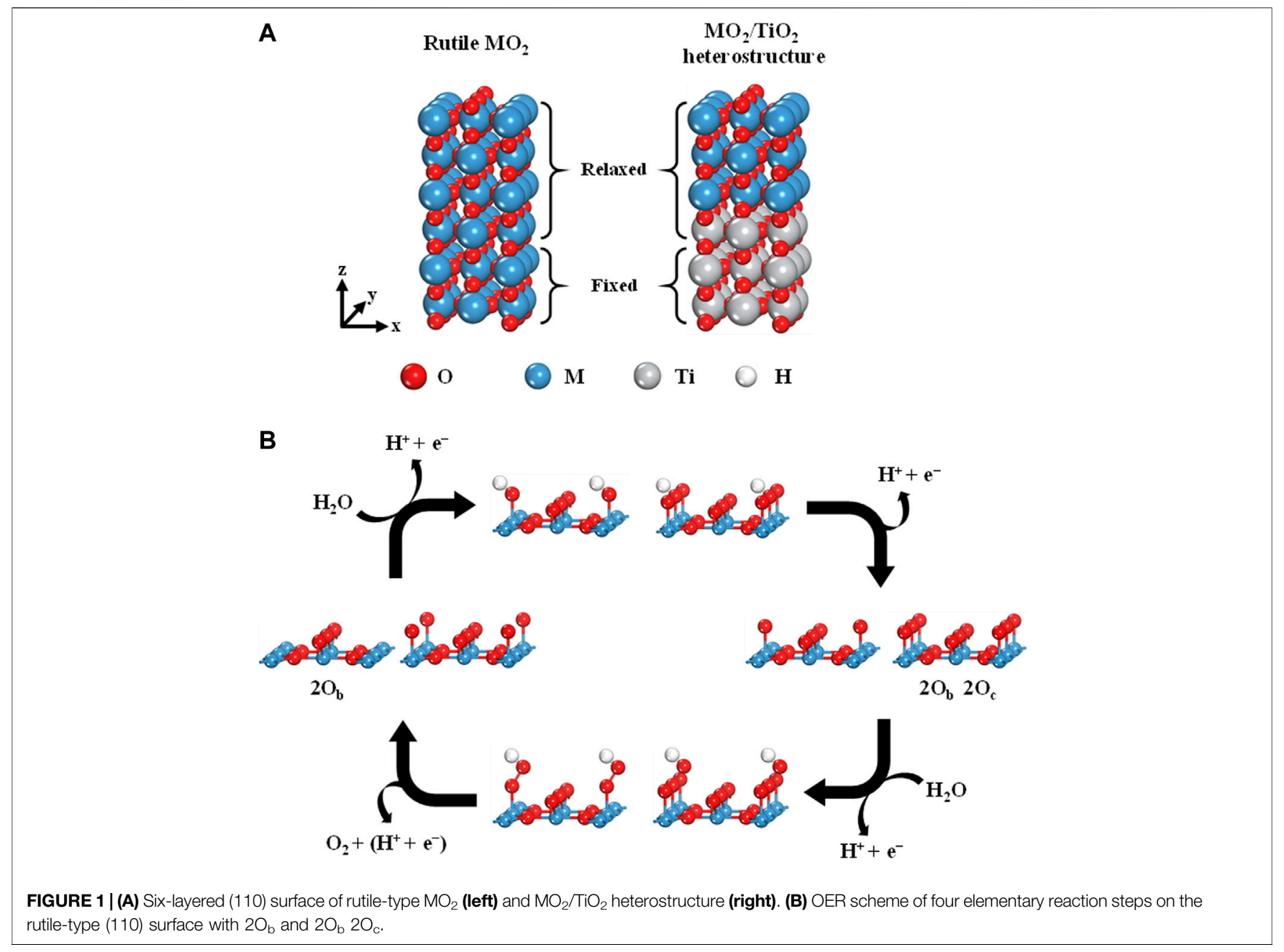

(i.e., $T=298 \mathrm{~K}$ and $\mathrm{pH}=0$ ). Free energy correction values were taken from Valdes et al.'s work (Valdes et al., 2008). The binding energy for each reaction intermediate (i.e., $\Delta E_{\mathrm{OH}^{*}}, \Delta E_{\mathrm{O}^{*}}$, and $\left.\Delta E_{\mathrm{OOH}^{*}}\right)$ was calculated as follows:

$$
\begin{gathered}
\Delta E_{\mathrm{OH}^{*}}=E\left(\mathrm{OH}^{*}\right)-E(*)-\left[E\left(\mathrm{H}_{2} \mathrm{O}\right)-0.5 E\left(\mathrm{H}_{2}\right)\right] \\
\Delta E_{\mathrm{O}^{*}}=E\left(\mathrm{O}^{*}\right)-E(*)-\left[E\left(\mathrm{H}_{2} \mathrm{O}\right)-E\left(\mathrm{H}_{2}\right)\right] \\
\Delta E_{\mathrm{OOH}^{*}}=E\left(\mathrm{OOH}^{*}\right)-E(*)-\left[2 E\left(\mathrm{H}_{2} \mathrm{O}\right)-1.5 E\left(\mathrm{H}_{2}\right)\right],
\end{gathered}
$$

where $E\left(\mathrm{OH}^{*}\right), E\left(\mathrm{O}^{*}\right)$, and $E\left(\mathrm{OOH}^{*}\right)$ represent the total energies of the slab models for each adsorbate, $E(*)$ is the total energy of the bare slab, and $E\left(\mathrm{H}_{2} \mathrm{O}\right)$ and $E\left(\mathrm{H}_{2}\right)$ represent the total energies of an isolated water molecule and hydrogen gas, respectively. The differences in the Gibbs free energy $(\Delta G)$ of each step were calculated as follows:

$$
\begin{gathered}
\Delta G_{1}=\Delta G_{\mathrm{OH}^{*}} \\
\Delta G_{2}=\Delta G_{\mathrm{O}^{*}}-\Delta G_{\mathrm{OH}^{*}} \\
\Delta G_{3}=\Delta G_{\mathrm{OOH}^{*}}-\Delta G_{\mathrm{O}^{*}} \\
\Delta G_{4}=4.92-\Delta G_{\mathrm{OOH}^{*}}
\end{gathered}
$$

Finally, the theoretical overpotential of the OER $\left(\eta_{\mathrm{OER}}\right)$ can be calculated as follows:

$$
\eta_{\mathrm{OER}}=\max \left(\left[\Delta G_{1}, \Delta G_{2}, \Delta G_{3}, \Delta G_{4}\right] / e\right)-U_{e q},
$$

where $U_{e q}$ indicates the equilibrium potential of the OER (i.e., $1.23 \mathrm{~V}$ vs. reversible hydrogen electrode). Eqs 1-13 assume that thermodynamics of the reaction steps is a valid descriptor for reaction kinetics based on the Brønsted-Evans-Polanyi (BEP) relations (Vojvodic et al., 2011), which refer to that a free-energy change in the transition states (kinetics) follows a change in the reaction heat (thermodynamics). Note that the connection between thermodynamics and kinetics is not always established (Kuo et al., 2017; Kuo et al., 2018), which requires further kinetic experiments or microkinetic modeling based on the activation barrier calculations for all plausible transition states.

We examined the scaling relations between the adsorption free energies of the reaction intermediates (i.e., $\mathrm{OH}^{*}, \mathrm{O}^{*}$, and $\mathrm{OOH}^{*}$; Supplementary Table S2) for all rutile-type catalysts of interest (Figure 2A). The binding energies of $\mathrm{OOH}^{\star}$ and $\mathrm{OH}^{\star}$ are linearly correlated, with an offset of $3.20 \mathrm{eV}$. Note that our scaling trend is 

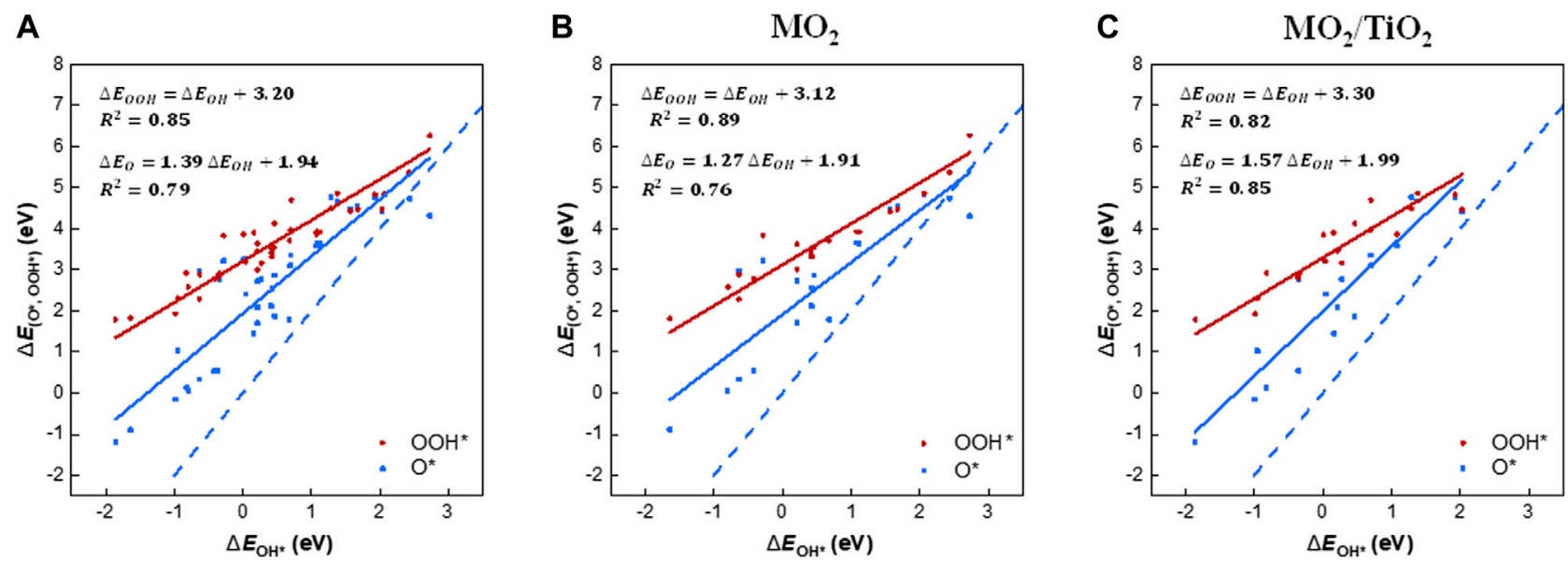

FIGURE 2 | Scaling relations of the binding energies of the OER intermediates (i.e., $\mathrm{OH}^{*}, \mathrm{O}^{*}$, and $\mathrm{OOH}^{*}$ ) with the binding energy of $\mathrm{OH}^{\star}$, which is the first intermediate for the OER. The diagrams contain the binding energies on the (110) surface of (A) all rutile-type oxides in this study, (B) $\mathrm{MO}_{2}$, and (C) $\mathrm{MO}_{2} / \mathrm{TiO}_{2}$ heterostructures, respectively. The solid lines are the linear trends of the binding energies of $\mathrm{OOH}^{*}(\mathrm{red})$ and $\mathrm{O}^{*}$ (blue) with respect to the binding energy of OH* The blue dashed line in all diagrams is the guideline of the $\mathrm{O}^{*}$ intermediate, which indicates the double bonding nature on the surface, with a slope of 2.
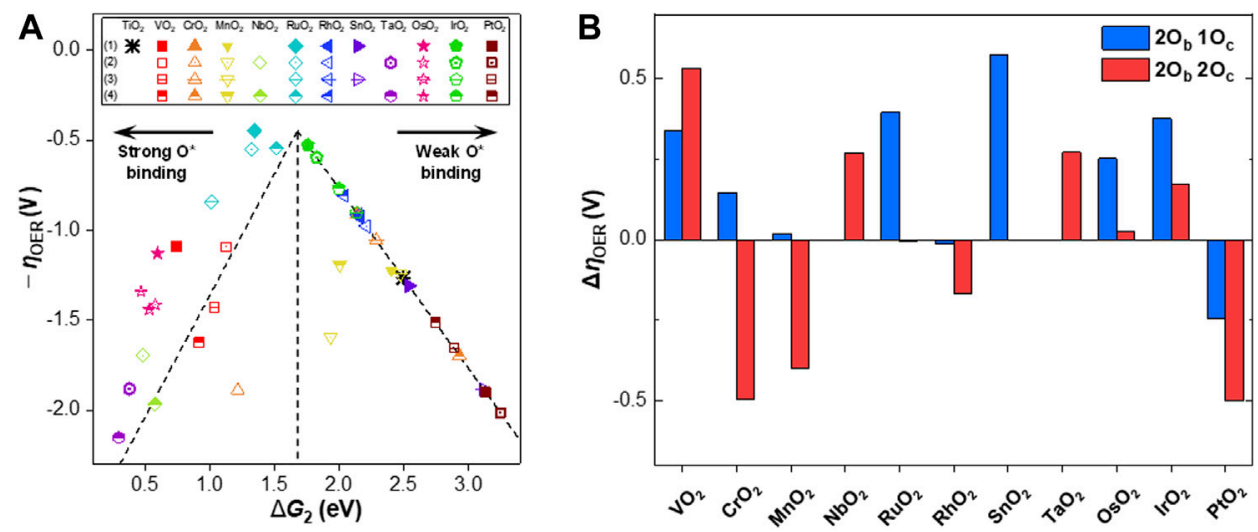

FIGURE 3 | (A) Volcano plot for the negative overpotential of the OER ( $-\eta_{\mathrm{OER}}$ ) as a function of $\Delta \mathrm{G}_{2}$. The numbers in the inset indicate each surface: 1 ) $2 \mathrm{O}_{\mathrm{b}}$ of $\mathrm{MO}_{2}$, 2) $2 \mathrm{O}_{\mathrm{b}} 2 \mathrm{O}_{\mathrm{c}}$ of $\mathrm{MO}_{2}$, 3) $2 \mathrm{O}_{\mathrm{b}}$ of $\mathrm{MO}_{2} / \mathrm{TiO}_{2}$, and 4) $2 \mathrm{O}_{\mathrm{b}} 2 \mathrm{O}_{\mathrm{c}}$ of $\mathrm{MO}_{2} / \mathrm{TiO}_{2}$. (cf. Supplementary Table S2). (B) Difference between the overpotentials of $\mathrm{MO}_{2}$ and $\mathrm{MO}_{2} / \mathrm{TiO} 2$ $\left[\Delta \eta_{\mathrm{OER}}=\eta_{\mathrm{OER}}\left(\mathrm{MO}_{2} / \mathrm{TiO}_{2}\right)-\eta_{\mathrm{OER}}\left(\mathrm{MO}_{2}\right)\right]$. A positive value of $\Delta \eta_{\mathrm{OER}}$ indicates the decrease in the OER activity and a negative $\Delta \eta_{\mathrm{OER}}$ reflects an enhancement.

similar to the "universal" scaling relation reported by Man et al. [i.e., $\Delta E_{\mathrm{OOH}^{*}}=\Delta E_{\mathrm{OH}^{*}}+3.20( \pm 0.20 \mathrm{eV})$ ] (Man et al., 2011), implying that all rutile-type systems, including heterostructures, follow the conventional scaling relations for metals and oxide surfaces. Based on the best fit, $68 \%$ of the points are within $\pm 0.35 \mathrm{eV}(1 \sigma)$ and $95 \%$ are within $\pm 0.70 \mathrm{eV}(2 \sigma)$. The scaling relationship between $\Delta E_{\mathrm{O}^{*}}$ and $\Delta E_{\mathrm{OH}^{*}}$ exhibits a slope of 1.39 (blue solid line), that is, it is much less steep than the slope of two (blue dashed line), which is the indicator line of the double bonding nature of $\mathrm{O}^{\star}$ (Rossmeisl et al., 2007).

To analyze the substrate effect of $\mathrm{TiO}_{2}$ on the heterostructures, we divided the scaling relations into two groups, that is, (110) surfaces of $\mathrm{MO}_{2}$ and $\mathrm{MO}_{2} / \mathrm{TiO}_{2}$ heterostructures (Figure 2B,C). Notably, the binding energies of $\mathrm{OOH}^{\star}$ and $\mathrm{O}^{\star}$ on the $\mathrm{MO}_{2} / \mathrm{TiO}_{2}$ (110) surface are more concentrated than those of $\mathrm{MO}_{2}$. The scaling relation between $\mathrm{OOH}^{\star}$ and $\mathrm{OH}^{\star}$ of $\mathrm{MO}_{2} / \mathrm{TiO}_{2}$ (red solid line) shows an increased intercept by 0.18 compared with the corresponding scaling relation of $\mathrm{MO}_{2}$, implying slightly weakened interactions between $\mathrm{OOH}^{*}$ and the surface. Note that the scaling relations between the binding strengths of $\mathrm{O}^{*}$ and $\mathrm{OH}^{\star}$ species on $\mathrm{MO}_{2}$ and $\mathrm{MO}_{2} / \mathrm{TiO}_{2}$ (blue solid lines) apparently differ. The slopes of $\mathrm{MO}_{2} / \mathrm{TiO}_{2}$ (110) heterostructures are closer to 2 (i.e., double bonding nature of $\mathrm{O}^{\star}$ ) than those of $\mathrm{MO}_{2}$ (110) surfaces (Rossmeisl et al., 2007). This is due to the intensified binding strengths of $\mathrm{O}^{*}$ intermediates in heterostructures compared with $\mathrm{MO}_{2}$ surfaces (Divanis et al., 2020). This indicates that the $\mathrm{TiO}_{2}$ substrate generally stabilizes the $\mathrm{O}^{*}$ intermediates, which might lead to a decrease in $\eta_{\mathrm{OER}}$ of rutile oxides involving weakly bound $\mathrm{O}^{*}$ intermediates.

Based on the scaling relations between the binding energies of the reaction intermediates, a volcano plot was constructed, as 

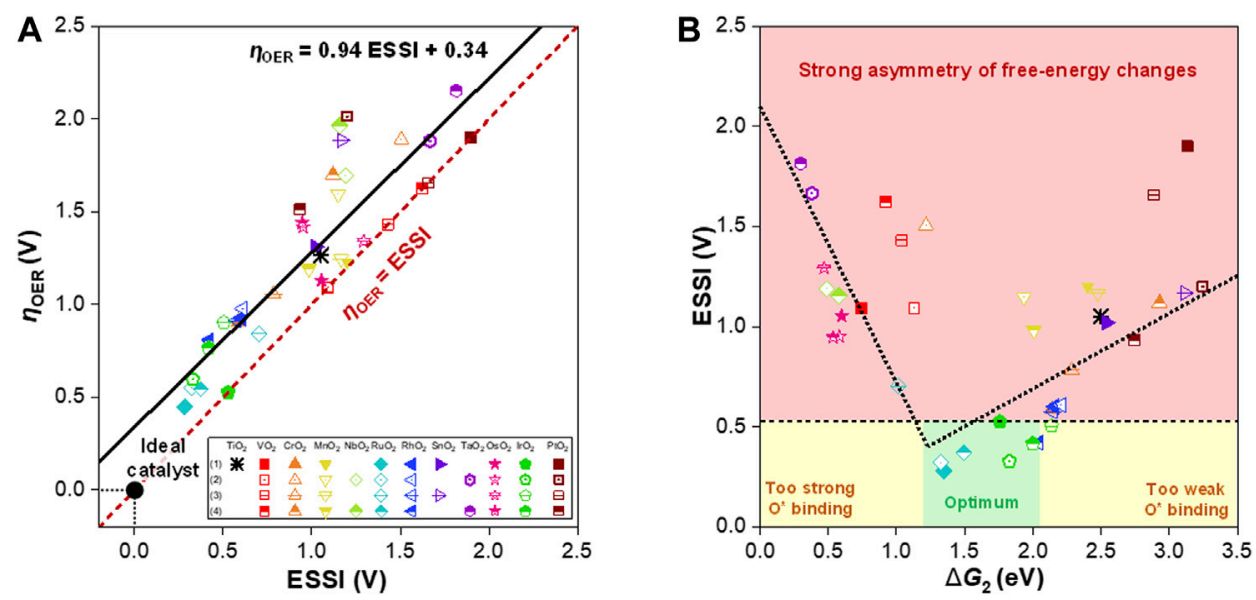

FIGURE 4 | (A) $\eta_{\mathrm{OER}}$ as a function of the ESSI. Black solid line indicates the linear relation between $\eta_{\mathrm{OER}}$ and ESSI. Red dotted line indicates the guideline of $\eta_{\mathrm{OER}}=$ ESSI. (B) ESSI- $\Delta G_{2}$ activity map. Three regions are classified depending on the OER activity - green area of $1.2 \mathrm{eV}<\Delta G_{2}<2.06 \mathrm{eV}$ with ESSI $<0.53 \mathrm{~V}$; yellow area of $\Delta G_{2}<1.2 \mathrm{eV}$ or $\Delta G_{2}>2.06 \mathrm{eV}$ with $\mathrm{ESSI}<0.53 \mathrm{~V}$; and red area of ESSI $>0.53 \mathrm{~V}$.

shown in Figure 3A. We chose $\Delta G_{\mathrm{O}^{*}}-\Delta G_{\mathrm{OH}^{*}}$ (denoted as $\Delta G_{2}$ ) as a descriptor, which is commonly used to predict the OER activity of the $4 \mathrm{e}^{-}$reaction (Man et al., 2011; Krishnamurthy et al., 2018). The plot shows that the $\mathrm{O}^{*}$ bonds of $\mathrm{PtO}_{2}, \mathrm{OsO}_{2}$, $\mathrm{TaO}_{2}$, and $\mathrm{RhO}_{2}$ on the $\mathrm{TiO}_{2}$ substrate are stronger than those without the $\mathrm{TiO}_{2}$ substrate, and the activities change along the volcano curve. In the cases of both oxygen coverages of $\mathrm{PtO}_{2} /$ $\mathrm{TiO}_{2}$ and $\mathrm{RhO}_{2} / \mathrm{TiO}_{2}, \Delta G_{2}$, which is the potential-determining step for each system, was reduced, exhibiting the improved OER activities (i.e., smaller $\left|\eta_{\text {OER }}\right|$ ) compared to those of $\mathrm{PtO}_{2}$ and $\mathrm{RhO}_{2}$, respectively. In the cases of $\mathrm{OsO}_{2}, \mathrm{TaO}_{2}$, and $\mathrm{NbO}_{2}$, the bonds of the $\mathrm{O}^{*}$ intermediates are too strong in the presence of the $\mathrm{TiO}_{2}$ substrate, resulting in a decreased OER activity.

Similar to the previous studies (Rossmeisl et al., 2007; Man et al., 2011), $\mathrm{RuO}_{2}$ and $\mathrm{IrO}_{2}$ were both identified as the active OER catalysts among the $\mathrm{MO}_{2}$ candidates (i.e., $\eta_{\mathrm{OER}}<\sim 0.5 \mathrm{~V}$, Figure 3A). In the case of $2 \mathrm{O}_{\mathrm{b}} 2 \mathrm{O}_{\mathrm{c}}$ of $\mathrm{RuO}_{2}$, the OER activity maintains similarity in the presence of $\mathrm{TiO}_{2}$ substrate, which is located near the top of the volcano. In general, the $\mathrm{TiO}_{2}$ substrate stabilizes the adsorbates (i.e., $\mathrm{OOH}^{\star}, \mathrm{O}^{\star}$, and $\mathrm{OH}^{\star}$ ) on $2 \mathrm{O}_{\mathrm{b}} 2 \mathrm{O}_{c}$ of $\mathrm{RuO}_{2}$, which appears as stronger adsorption free energies by 0.54-0.70 eV (Supplementary Table S1). Nevertheless, $\eta_{O E R}$ is almost unchanged (i.e., $\Delta \eta_{\mathrm{OER}}=-0.01 \mathrm{~V}$ ) because the free energy change in the potential determining step (i.e., $\Delta G_{\mathrm{OOH}^{*}}-\Delta G_{\mathrm{O}^{*}}$ ) remains similar (Supplementary Table S2). In addition, it is also noteworthy that $\eta_{\mathrm{OER}}$ for $2 \mathrm{O}_{\mathrm{b}} 2 \mathrm{O}_{\mathrm{c}}$ of $\mathrm{IrO}_{2}$ is relatively similar, still exhibiting higher activity than other candidates except $\mathrm{RuO}_{2}$.

The changes in $\eta_{\text {OER }}$ induced by the $\mathrm{TiO}_{2}$ substrate are summarized in Figure $\mathbf{3 B}$. As the value becomes more negative, the activity of $\mathrm{MO}_{2} / \mathrm{TiO}_{2}$ improves compared with that of $\mathrm{MO}_{2}$. Notably, $2 \mathrm{O}_{\mathrm{b}} 2 \mathrm{O}_{\mathrm{c}}$ of $\mathrm{CrO}_{2}, \mathrm{MnO}_{2}, \mathrm{RuO}_{2}, \mathrm{RhO}_{2}$, and $\mathrm{PtO}_{2}$ shows an enhanced activity. In addition, $2 \mathrm{O}_{\mathrm{b}}$ of $\mathrm{RhO}_{2}$ and $\mathrm{PtO}_{2}$ also shows an improved activity on the $\mathrm{TiO}_{2}$ substrate. However, regardless of the coverage, the $\mathrm{TiO}_{2}$ substrate decreases the OER activity of $\mathrm{VO}_{2}, \mathrm{OsO}_{2}$, and $\mathrm{IrO}_{2}$. In particular, $2 \mathrm{O}_{\mathrm{b}} 2 \mathrm{O}_{\mathrm{c}}$ of $\mathrm{VO}_{2}$ and $2 \mathrm{O}_{\mathrm{b}}$ of $\mathrm{SnO}_{2}$ exhibit significantly increased overpotentials $\left(\Delta \eta_{\mathrm{OER}}\right.$ of 0.53 and $0.57 \mathrm{~V}$, respectively).

To determine the promising free-energy regime for the OER, we further analyzed the free energies of the steps in terms of the ESSI, as suggested by Calle-Vallejo and coworkers (Govindarajan et al., 2018). The ESSI is an energetic descriptor that indicates the degree of similarity with an ideal catalyst, where all OER steps are perfectly symmetric at $1.23 \mathrm{eV}$. The ESSI is defined by the following equation and is only applied to steps with $\Delta G_{i}(i=1,2,3,4) \geq 1.23 \mathrm{eV}\left(\right.$ denoted as $\left.\Delta G_{i}^{*}\right)$ :

$$
\mathrm{ESSI}=\frac{1}{n} \sum_{i}^{n}\left(\Delta G_{i}^{*}-1.23\right) \text {. }
$$

Figure 4A shows $\eta_{\mathrm{OER}}$ of each model as a function of the ESSI, representing a good linear correlation. $2 \mathrm{O}_{\mathrm{b}}$ of $\mathrm{RuO}_{2}$ is the closest model to the ideal catalyst, followed by $2 \mathrm{O}_{b} 2 \mathrm{O}_{c}$ of $\mathrm{RuO}_{2}$ and $\mathrm{RuO}_{2} / \mathrm{TiO}_{2}$. The $2 \mathrm{O}_{\mathrm{b}}$ of $\mathrm{PtO}_{2}$ appears on the $\eta_{\mathrm{OER}}=\mathrm{ESSI}$ (red dashed line) and has a null bar with respect to the ESSI, which means that only a single step is greater than $1.23 \mathrm{~V}$ (i.e., $\Delta G_{2}=$ $3.13 \mathrm{eV})$. In the presence of the $\mathrm{TiO}_{2}$ substrate, $\Delta G_{2}$ for $2 \mathrm{O}_{\mathrm{b}}$ of $\mathrm{PtO}_{2}$ is reduced, leading to a decrease of the ESSI and $\eta_{\mathrm{OER}}$. Meanwhile, $2 \mathrm{O}_{\mathrm{b}} 2 \mathrm{O}_{\mathrm{c}}$ of $\mathrm{PtO}_{2}$ lies relatively far from the line of $\eta_{\mathrm{OER}}=$ ESSI, which has a wide bar with respect to the ESSI, and thus corresponds to a good candidate for optimization (Govindarajan et al., 2018). In practice, the $\mathrm{TiO}_{2}$ substrate on $2 \mathrm{O}_{\mathrm{b}} 2 \mathrm{O}_{\mathrm{c}}$ of $\mathrm{PtO}_{2}$ works for enhancing the OER activity with a decrease in both $\eta_{\text {OER }}$ and ESSI.

Based on the scaling relation between the ESSIs and $\eta_{O E R}$ 's, we determined a promising group of OER catalysts using the ESSI- $\Delta G_{2}$ activity map introduced by Exner (Exner, 2019; Figure 4B). The activity map is used to identify OER candidates by adjusting the ESSI threshold. The ESSI threshold $(<0.53 \mathrm{~V})$ was determined from Supplementary Figure S2 by applying $\eta_{\mathrm{OER}}$ of $\mathrm{IrO}_{2}$, which is the conventional OER catalyst. The free-energy regime was set to $1.20 \mathrm{eV}<\Delta G_{2}<2.06 \mathrm{eV}$ by 
applying the standard deviation of $\pm 0.43 \mathrm{eV}$ of the scaling relationship between $\Delta G_{2}$ and $\Delta G_{3}$ (Supplementary Figure S3) on $1.63 \mathrm{eV}$. The median value of $1.63 \mathrm{eV}$ in the free-energy regime is determined by assuming the threshold electrode potential as the point where the experimental Tafel slope exceeds $59 \mathrm{mV} / \mathrm{dec}$ (i.e., $\eta_{\mathrm{OER}}>0.4 \mathrm{~V}$ ), accounting for kinetics (Exner and Over, 2019). The green-colored area includes $2 \mathrm{O}_{b}$ of $\mathrm{RuO}_{2}, 2 \mathrm{O}_{\mathrm{b}} 2 \mathrm{O}_{\mathrm{c}}$ of $\mathrm{RuO}_{2}, 2 \mathrm{O}_{\mathrm{b}} 2 \mathrm{O}_{\mathrm{c}}$ of $\mathrm{RuO}_{2} / \mathrm{TiO}_{2}, 2 \mathrm{O}_{\mathrm{b}}$ of $\mathrm{IrO}_{2}, 2 \mathrm{O}_{\mathrm{b}} 2 \mathrm{O}_{\mathrm{c}}$ of $\mathrm{IrO}_{2}, 2 \mathrm{O}_{\mathrm{b}}$ $2 \mathrm{O}_{\mathrm{c}}$ of $\mathrm{IrO}_{2} / \mathrm{TiO}_{2}$, and $2 \mathrm{O}_{\mathrm{b}} 2 \mathrm{O}_{\mathrm{c}}$ of $\mathrm{RhO}_{2}$, which are the most promising candidates. Particularly, a portion of promising candidates for the OER (i.e., $\mathrm{RuO}_{2}, \mathrm{RuO}_{2} / \mathrm{TiO}_{2}, \mathrm{IrO}_{2}, \mathrm{IrO}_{2} /$ $\mathrm{TiO}_{2}$, and $\mathrm{RhO}_{2} / \mathrm{TiO}_{2}$ ) are more evidently classified on the ESSI- $\Delta G_{2}$ map (Figure 4B), while they are somewhat deviated from the apex in the volcano plot (Figure 3A). This implies that conventional volcano analysis does not guarantee to predict the most active OER catalyst, whereas the ESSI- $\Delta G_{2}$ activity map, which is based on the kinetic scaling relations, is a more robust descriptor for the OER (Exner, 2019; Exner and Over, 2019). The $2 \mathrm{O}_{\mathrm{b}} 2 \mathrm{O}_{\mathrm{c}}$ surface of $\mathrm{IrO}_{2}$ exhibits high symmetry of the reaction steps comparable to $\mathrm{RuO}_{2}$. On the $2 \mathrm{O}_{\mathrm{b}}$ and $2 \mathrm{O}_{\mathrm{b}} 2 \mathrm{O}_{\mathrm{c}}$ surfaces of $\mathrm{RhO}_{2} / \mathrm{TiO}_{2}$, the values of $\Delta G_{2}$ decrease compared to those of $\mathrm{RhO}_{2}$. Accordingly, the free-energy differences of the other steps are adjusted to compensate for the decrease in $\Delta G_{2}$, while maintaining $\Delta G_{2}$ as a potential-determining step with reduced $\eta_{\text {OER }}$ (cf. Supplementary Table S2). Next, $2 \mathrm{O}_{\mathrm{b}}$ of $\mathrm{IrO}_{2} / \mathrm{TiO}_{2}$ belongs to the yellow-colored region, which needs to be reconsidered for activity optimization (Govindarajan et al., 2019). The candidates in the region of ESSI > $0.53 \mathrm{~V}$ (i.e., redhighlighted region in Figure $\mathbf{4 B}$ ) are classified as an inferior group, showing poor OER activities over all ranges of $\Delta G_{2}$ due to the highly asymmetric free-energy changes of the OER intermediates (Exner, 2019).

\section{CONCLUSION}

We screened a variety of rutile oxide heterostructures based on a $\mathrm{TiO}_{2}$ substrate using scaling relations and relevant descriptors to identify a promising OER catalyst. The scaling relations between the reaction intermediates demonstrate that the rutile-type $\mathrm{MO}_{2}$ heterostructures follow the universal scaling relationship of metal oxides. In addition, the $\mathrm{TiO}_{2}$ substrate stabilizes the $\mathrm{O}^{\star}$ bond on the (110) metal oxide surface. Based on the conventional volcano plot, $\mathrm{RuO}_{2}$ and $\mathrm{IrO}_{2}$ are found to be highly active OER catalysts as previously reported. Based on the ESSI descriptor, the superior activity of the $\mathrm{RuO}_{2}$ can be

\section{REFERENCES}

Anisimovdag, V. I., Aryasetiawan, F., and Lichtenstein, A. I. (1997). First-principles calculations of the electronic structure and spectra of strongly correlated systems: the LDA + U method. J. Phys. Condens. Matter 9, 767-808. doi:10.1088/0953-8984/9/4/002

Blochl, P. E. (1994). Projector augmented-wave method. Phys. Rev. B 50, 17953. doi:10.1103/PhysRevB.50.17953

Bu, Y., Jang, H., Gwon, O., Kim, S. H., Joo, S. H., Nam, G., et al. (2019). Synergistic interaction of perovskite oxides and $\mathrm{N}$-doped graphene in versatile electrocatalyst. J. Mater. Chem. A 7 (5), 2048-2054. doi:10.1039/c8ta09919g attributed to the high symmetry of the reaction steps. Furthermore, based on the ESSI- $\Delta G_{2}$ activity map, the candidates can be classified into an optimum group, a second promising group of OER catalysts with potential for optimization, and an inferior group that does not require particular attention.

The results of our computational screening using the scaling relations of rutile-type heterostructures provide valuable insights into the effect of the support material on the overpotential and thus guidelines for the design of a promising OER catalyst.

\section{DATA AVAILABILITY STATEMENT}

The original contributions presented in the study are included in the article/Supplementary Material, further inquiries can be directed to the corresponding authors.

\section{AUTHOR CONTRIBUTIONS}

All calculations and data analyses were performed by HYL. All authors contributed to the discussion of the results and wrote and revised the manuscript. SKK and GYJ supervised the project.

\section{FUNDING}

This work was supported by the National Research Foundation of Korea (NRF) grant funded by the Korea government (Ministry of Science and ICT) (NRF-2019M1A2A2065614) and the Global PhD Fellowship Program (NRF-2019H1A2A1076827 and NRF2016H1A2A1908137). SKK acknowledges the UNIST grant (2.200487.01) for the support of the publication. Computational resources were provided by UNIST High Performance Computing (HPC) systems and Korea Institute of Science and Technology Information (KISTI) (KSC-2019CRE-0255).

\section{SUPPLEMENTARY MATERIAL}

The Supplementary Material for this article can be found online at: https://www.frontiersin.org/articles/10.3389/fenrg.2021.606313/ full\#supplementary-material.

Costentin, C., and Savéant, J.-M. (2017). Theoretical and mechanistic aspects of proton-coupled electron transfer in electrochemistry. Curr. Opin. Electrochem. 1, 104-109. doi:10.1016/j.coelec.2016.11.001

Divanis, S., Kutlusoy, T., Boye, I. M. I., Man, I. C., and Rossmeisl, J. (2020). Oxygen evolution reaction: a perspective on a decade of atomic scale simulations. Chem. Sci. 11, 2943. doi:10.1039/c9sc05897d

Esposito, D. V., Hunt, S. T., Stottlemyer, A. L., Dobson, K. D., McCandless, B. E., Birkmire, R. W., et al. (2010). Low-cost hydrogen-evolution catalysts based on monolayer platinum on tungsten monocarbide substrates. Angew. Chem. Int. Ed. 49, 9859-9862. doi:10.1002/anie. 201004718 
Exner, K. S. (2019). Design criteria for oxygen evolution electrocatalysts from first principles: introduction of a unifying material-screening approach. ACS Appl. Energy Mater. 2, 11. doi:10.1021/acsaem.9b01480

Exner, K. S., and Over, H. (2019). Beyond the rate-determining step in the oxygen evolution reaction over a single-crystalline $\mathrm{IrO}_{2}(110)$ model electrode: kinetic scaling relations. ACS Catal. 9, 6755-6765. doi:10.1021/acscatal.9b01564

Frydendal, R., Paoli, E. A., Knudsen, B. P., Wickman, B., Malacrida, P., Stephens, I. E. L., et al. (2014). Benchmarking the stability of oxygen evolution reaction catalysts: the importance of monitoring mass losses. ChemElectroChem. 1, 2075-2081. doi:10.1002/celc.201402262

García-Mota, M., Vojvodic, A., Metiu, H., Man, I. C., Su, H.-Y., Rossmeisl, J., et al. (2011). Tailoring the activity for oxygen evolution electrocatalysis on rutile $\mathrm{TiO}_{2}(110)$ by transition-metal substitution. ChemCatChem. 3, 1607-1611. doi:10.1002/cctc. 201100160

Govindarajan, N., Garcia-Lastra, J. M., Meijer, E. A., and Calle-Vallejo, F. (2018). Does the breaking of adsorption-energy scaling relations guarantee enhanced electrocatalysis? Curr. Opin. Electrochem. 8, 110-117. doi:10.1016/j.coelec.2018. 03.025

Govindarajan, N., Koper, M. T. M., Meijer, E. J., and Calle-Vallejo, F. (2019). Outlining the scaling-based and scaling-free optimization of electrocatalysts. ACS Catal. 9, 4218-4225. doi:10.1021/acscatal.9b00532

Hammes-Schiffer, S. (2015). Proton-coupled electron transfer: moving together and charging forward. J. Am. Chem. Soc. 137, 8860-8871. doi:10.1021/jacs. $5 \mathrm{~b} 04087$

Hanaor, D. A. H., Xu, W., Ferry, M., and Sorrell, C. C. (2012). Abnormal grain growth of rutile $\mathrm{TiO}_{2}$ induced by $\mathrm{ZrSiO}_{4}$. J. Cryst. Growth 359, 83-91. doi:10. 1016/j.jcrysgro.2012.08.015

Jin, B., Zhou, X., Huang, L., Licklederer, M., Yang, M., and Schmuki, P. (2016). Aligned $\mathrm{MoO}_{\mathrm{x}} / \mathrm{MoS}_{2}$ core-shell nanotubular structures with a high density of reactive sites based on self-ordered anodic molybdenum oxide nanotubes. Angew. Chem., Int. Ed. Engl. 55, 12252. doi:10.1002/anie.201605551

Kresse, G., and Furthmiiller, J. (1996). Efficiency of ab-initio total energy calculations for metals and semiconductors using a plane-wave basis set. Comput. Mater. Sci. 6, 15-50. doi:10.1016/0927-0256(96)00008-0

Krishnamurthy, D., Sumaria, V., and Viswanathan, V. (2018). Maximal predictability approach for identifying the right descriptors for electrocatalytic reactions. J. Phys. Chem. Lett. 9, 588-595. doi:10.1021/acs. jpclett.7b02895

Kumar, K., Canaff, C., Rousseau, J., Arrii-Clacens, S., Napporn, T. W., Habrioux, A., et al. (2016). Effect of the oxide-carbon heterointerface on the Activity of $\mathrm{Co}_{3} \mathrm{O}_{4} / \mathrm{NRGO}$ nanocomposites toward ORR and OER. J. Phys. Chem. C 120 (15), 7949-7958. doi:10.1021/acs.jpcc.6b00313

Kung, H. H. (1989). Transition metal oxides: surface chemistry and catalysis. Amsterdam: Elsevier Science.

Kuo, D. Y., Kawasaki, J. K., Nelson, J. N., Kloppenburg, J., Hautier, G., Shen, K. M., et al. (2017). Influence of surface adsorption on the oxygen evolution reaction on $\mathrm{IrO}_{2}(110)$. J. Am. Chem. Soc. 139, 3473-3479. doi:10.1021/jacs.6b11932

Kuo, D. Y., Paik, H., Kloppenburg, J., Faeth, B., Shen, K. M., Schlom, D. G., et al. (2018). Measurements of oxygen electroadsorption energies and oxygen evolution reaction on $\mathrm{RuO}_{2}(110)$ : a discussion of the sabatier principle and its role in electrocatalysis. J. Am. Chem. Soc. 140, 17597-17605. doi:10.1021/ jacs.8b09657

Lee, Y., Suntivich, J., May, K. J., Perry, E. E., and Shao-Horn, Y. (2012). Synthesis and activities of rutile $\mathrm{IrO}_{2}$ and $\mathrm{RuO}_{2}$ nanoparticles for oxygen evolution in acid and alkaline solutions. J. Phys. Chem. Lett. 3 (3), 399-404. doi:10.1021/jz2016507

Li, X., Sun, X., Xu, X., Liu, W., Peng, H., Fang, X., et al. (2017). CO oxidation on $\mathrm{PdO}$ catalysts with perfect and defective rutile- $\mathrm{TiO}_{2}$ as supports: elucidating the role of oxygen vacancy in support by DFT calculations. Appl. Surf. Sci. 401, 49-56. doi:10.1016/j.apsusc.2016.12.210

Lu, X. F., Chen, Y., Wang, S. B., Gao, S. Y., and Lou, X. W. (2019). Interfacing manganese oxide and cobalt in porous graphitic carbon polyhedrons boosts oxygen electrocatalysis for Zn-Air batteries. Adv. Mater. 31 (39), 1902339. doi:10.1002/adma.201902339

Man, I. C., Su, H.-Y., Calle-Vallejo, F., Hansen, H. A., Martínez, J. I., Inoglu, N. G., et al. (2011). Universality in oxygen evolution electrocatalysis on oxide surfaces. ChemCatChem. 3, 1159-1165. doi:10.1002/cctc.201000397

Oh, N. K., Kim, C., Lee, J., Kwon, O., Choi, Y., Jung, G. Y., et al. (2019). In-situ local phase-transitioned $\mathrm{MoSe}_{2}$ in $\mathrm{La}_{0.5} \mathrm{Sr}_{0.5} \mathrm{CoO}_{3-\delta}$ heterostructure and stable overall water electrolysis over 1000 hours. Nat. Commun. 10, 1723. doi:10.1038/ s41467-019-09339-y

Perdew, J. P., Burke, K., and Ernzerhof, M. (1997). Generalized gradient approximation made simple. Phys. Rev. Lett. 77, 3865. doi:10.1103/ PhysRevLett.77.3865

Qingxiang, W., Dastafkan, K., and Chuan, Z. (2018). Design strategies for nonprecious metal oxide electrocatalysts for oxygen evolution reactions. Curr. Opin. Electrochem. 10, 16-23. doi:10.1016/j.coelec.2018.03.015

Rossmeisl, J., Qu, Z.-W., Zhu, H., Kroes, G.-J., and Nørskov, J. K. (2007). Electrolysis of water on oxide surfaces. Electroanal. Chem. 607, 83. doi:10. 1016/j.jelechem.2006.11.008

Seitsonen, A. P., and Over, H. (2010). Oxidation of $\mathrm{HCl}$ over $\mathrm{TiO}_{2}$-supported $\mathrm{RuO}_{2}$ : a density functional theory study. J. Phys. Chem. C 114, 22624-22629. doi:10.1021/jp108603a

Seitz, L. C., Dickens, C. F., Nishio, K., Hikita, Y., Montoya, J., Doyle, A., et al. (2016). A highly active and stable $\mathrm{IrO}_{\mathrm{x}} / \mathrm{SrIrO}_{3}$ catalyst for the oxygen evolution reaction. Science 353 (6303), 1011-1014. doi:10.1126/science.aaf5050

Stacchiola, D. J., Senanayake, S. D., Liu, P., and Rodriguez, J. A. (2013). Fundamental studies of well-defined surfaces of mixed-metal oxides: special properties of $\mathrm{MO}_{\mathrm{x}} / \mathrm{TiO}_{2}(110)\{\mathrm{M}=\mathrm{V}, \mathrm{Ru}, \mathrm{Ce}$, or $\mathrm{W}\}$. Chem. Rev. 113, 4373-4390. doi:10.1021/cr300316v

Suen, N.-T., Hung, S.-F., Quan, Q., Zhang, N., Xu, Y.-J., and Chen, H. M. (2017). Electrocatalysis for the oxygen evolution reaction: recent development and future perspectives. Chem. Soc. Rev. 46 (337), 337-365. doi:10.1039/ c6cs00328a

Sun, X., Peng, X., Xu, X., Jin, H., Wang, H., and Wang, X. (2016). $\mathrm{H}_{2}$ adsorption and dissociation on $\mathrm{PdO}(101)$ films supported on rutile $\mathrm{TiO}_{2}(110)$ facet: elucidating the support effect by DFT calculations. J. Mol. Model. 22, 204. doi:10.1007/s00894-016-3072-3

Turner, J. A. (2004). Sustainable hydrogen production. Science 305, 972-974. doi:10.1126/science.1103197

Valdes, A., Qu, Z.-W., Kroes, G.-J., Rossmeisl, J., and Norskov, J. K. (2008). Oxidation and photo-oxidation of water on $\mathrm{TiO}_{2}$ surface. J. Phys. Chem. C 2, 9872-9879. doi:10.1021/jp711929d

Vojvodic, A., Calle-Vallejo, F., Guo, W., Wang, S., Toftelund, A., Studt, F., et al. (2011). On the behavior of Brønsted-Evans-Polanyi relations for transition metal oxides. J. Chem. Phys. 134, 244509. doi:10.1063/1.3602323

Wang, D. Y., Gong, M., Chou, H. L., Pan, C. J., Chen, H. A., Wu, Y., et al. (2015). Highly active and stable hybrid catalyst of cobalt-doped $\mathrm{FeS}_{2}$ nanosheets-carbon nanotubes for hydrogen evolution reaction. J. Am. Chem. Soc. 137, 1587. doi:10.1021/jacs.5b07788

Wei, W., Dai, Y., Huang, B., Li, X., Nagele, F., Over, H., et al. (2015). Density functional characterization of the electronic structures and band bending of rutile $\mathrm{RuO}_{2} / \mathrm{TiO}_{2}(110)$ heterostructures. J. Phys. Chem. C 119, 12394-12399. doi:10.1021/acs.jpcc.5b01884

Xiao, Z., Huang, Y.-C., Dong, C.-L., Xie, C., Liu, Z., Du, S., et al. (2020). Operando identification of the dynamic behavior of oxygen vacancy-rich $\mathrm{Co}_{3} \mathrm{O}_{4}$ for oxygen evolution reaction. J. Am. Chem. Soc. 142, 12087. doi:10.1021/jacs. 0c00257

Xu, Z., Rossmeisl, J., and Kitchin, J. R. (2015). A linear response DFT+U study of trends in the oxygen evolution activity of transition metal rutile dioxides. J. Phys. Chem. C 119, 4827-4833. doi:10.1021/jp511426q

Zhou, W., Hou, D., Sang, Y., Yao, S., Zhou, J., Li, G., et al. (2014). $\mathrm{MoO}_{2}$ nanobelts@nitrogen self-doped $\mathrm{MoS}_{2}$ nanosheets as effective electrocatalysts for hydrogen evolution reaction. J. Mater. Chem. A 2, 11358. doi:10.1039/ c4ta01898b

Conflict of Interest: The authors declare that the research was conducted in the absence of any commercial or financial relationships that could be construed as a potential conflict of interest.

Copyright $\odot 2021$ Lim, Park, Kim, Jung and Kwak. This is an open-access article distributed under the terms of the Creative Commons Attribution License (CC BY). The use, distribution or reproduction in other forums is permitted, provided the original author(s) and the copyright owner(s) are credited and that the original publication in this journal is cited, in accordance with accepted academic practice. No use, distribution or reproduction is permitted which does not comply with these terms. 